\title{
The efficacy of psychological interventions on psoriasis treatment: a systematic review and meta-analysis of randomized controlled trials
}

This article was published in the following Dove Medical Press journal: Psychology Research and Behavior Management

\author{
Yi Xiao ${ }^{1-3, *}$ \\ Xingyu Zhang ${ }^{4, *}$ \\ Dan Luo ${ }^{4}$ \\ Yehong Kuang ${ }^{1-3}$ \\ Wu Zhu'-3 \\ Xiang Chen ${ }^{1-3}$ \\ Minxue Shen ${ }^{1-3}$
}

'Department of Dermatology, Xiangya Hospital, Central South University, Changsha, China; ${ }^{2}$ Hunan Engineering Research Center of Skin Health and Disease, Central South University, Changsha, China; ${ }^{3}$ Hunan Key Laboratory of Skin Cancer and Psoriasis, Central South University, Changsha, China; ${ }^{4}$ Department of Social Medicine and Health Management, Xiangya School of Public Health, Central South University, Changsha, China

*These authors contributed equally to this work
Correspondence: Xiang Chen;

Minxue Shen

Department of Dermatology, Central

South University, Xiangya Hospital,

87 Xiangya Road, Changsha,

Hunan 410008, China

Tel +86 I59 73I6 4022

Email xysm20II@yeah.net;

shenmx1988@csu.edu.cn
Background: Previous observational studies have shown comorbidity between psoriasis and psychological disorders. However, the evidence of the efficacy of psychological interventions, including cognitive behavioral therapy (CBT) and other treatments, on psoriasis is still debated. Objectives: The aim of this study was to systematically review the psychological interventions used in the treatment of psoriasis and to meta-analyze the efficacy of psychological interventions on psoriasis with respect to area and severity reduction.

Materials and methods: A systematic review and meta-analysis were conducted. PubMed, Web of Science, EMbase, and major Chinese academic journal databases were searched for articles published before January 2018. Studies of randomized controlled trials (RCTs) that applied psychological interventions in the treatment of psoriasis and used area and severity as the outcome measures were meta-analyzed. The pooled mean difference between groups was estimated using either fixed-effects models or random-effects models in the presence of heterogeneity. Subgroup analysis was performed by method of intervention and severity of psoriasis. Results: Out of the 4,152 potentially relevant studies, 8 RCTs were included. The pooled mean difference was $-1.36(95 \% \mathrm{CI}:-2.52$ to $-0.19 ; P=0.02)$. The pooled estimate was $-1.80(95 \% \mathrm{CI}$ : -2.57 to $-1.03 ; P<0.001)$ for $\mathrm{CBT}$ intervention and was -0.70 (95\% CI: -2.39 to $0.99 ; P=0.42)$ for non-CBT intervention. The pooled estimates for mild and moderate-to-severe psoriasis were -1.95 (95\% CI: -3.91 to $0.00 ; P=0.05$ ) and -0.61 (95\% CI: -1.61 to $0.38 ; P=0.23$ ), respectively. Conclusion: $\mathrm{CBT}$ is effective in the treatment of psoriasis in terms of area and severity reduction. Systemic treatment does not further enhance the efficacy of CBT. The effect of the psychological intervention is stronger in patients with moderate-to-severe psoriasis.

Keywords: psoriasis, psychological intervention, cognitive behavioral therapy, randomized controlled trial, meta-analysis

\section{Introduction}

Psoriasis is a chronic inflammatory skin disease that affects $1 \%-3 \%$ of the general population, ${ }^{1}$ involving over 125 million individuals worldwide. ${ }^{2}$ Characterized by scaly skin lesions and frequent itching, psoriasis can affect the patient's health-related quality of life physiologically and psychologically. ${ }^{3,4}$ Besides the fact that psoriasis is a systemic disease, not only involving skin but also pathologically interwoven with a wide range of comorbidities, including inflammatory arthritis, cardiometabolic disorders, metabolic disorders, oral mucosal lesions, mental disorders, etc, it further increased the overall burden of patients. ${ }^{5-12}$

An increased prevalence of mental disorders such as depression and anxiety has been observed in patients with psoriasis. ${ }^{13,14}$ Depression is also associated with an 
increased incidence of psoriasis according to a longitudinal study. ${ }^{15}$ Their interaction has been widely explored and explained in multidimensions, including stigmatization from experience of helplessness and social isolation, ${ }^{16}$ related inflammatory cytokines, ${ }^{17}$ etc. According to the new concept "syndemics", ${ }^{18}$ psoriasis and mental disorders can be considered a pair of syndemics since they are mutually influential on both physiological and social levels; this suggests that they might be exacerbated or alleviated at the same time. In recent years, several attempts have been made to explore whether psychological intervention is effective to relieve both psoriasis and mental disorders. ${ }^{19-23}$ However, large heterogeneities with respect to the method and length of intervention, the evaluation of outcomes, and efficacy exist in the literature. This study aims to systematically review related randomized controlled trials (RCTs) reporting the efficacy of psychological interventions on psoriasis severity.

\section{Materials and methods Data searches and sources}

We searched PubMed, Web of Science, EMbase, the Chinese Biomedical Literature Database, the Wanfang Database, and the Chinese National Knowledge Infrastructure data of Chinese journals. The searching strategy and keywords used for PubMed are described subsequently.

1. Psoriasis OR psoriatic

2. Intervention OR therapy OR treatment

3. Mental OR emotional OR psychological OR cognitive OR educational

4. \#1 AND \#2 AND \#3.

Articles published before January 2018, in English or Chinese, were searched. The search strategy adjusts to a controlled vocabulary for each database. We also reviewed references in review articles. Gray literature and conference abstracts have not been searched.

\section{Study selection}

Studies were considered to be potentially eligible if they: 1) were RCT; 2) evaluated depression or anxiety in conjunction with psoriasis; 3) included a control group; 4) assessed psoriasis by the Psoriasis Area and Severity Index (PASI), Self-administered Psoriasis Area and Severity Index (SAPASI), or body surface area (BSA). If the same population was researched in more than one study, we included the study with the longest follow-up time or the most detailed information.

\section{Data extraction and quality assessment}

The background data of the studies were extracted including research design (randomization and patient allocation, length of follow-up), study objects (age, the severity of psoriasis, and emotional problems), and intervention (duration of intervention, type of intervention, and therapy format). Mean values and SDs of outcome measures were extracted for meta-analysis.

The Jadad scale was used to evaluate the quality of studies, with values of $0-2$ assigned to study design, explanations of the missing, and blinding of the study. ${ }^{24}$ Studies with a score of $0-2$ were categorized as lower quality, whereas studies with scores of 3-5 were categorized as higher quality. Two independent reviewers assessed eligibility criteria and extracted data, and any disagreements were resolved by discussion.

\section{Statistical analysis}

For each study, the measures assessing area or severity of psoriasis (in terms of PASI, SAPAI, or BSA) reduction were extracted. Effect sizes were calculated as mean difference, namely, the difference in mean values between the intervention group and the control group. Homogeneity of effect size was tested by using the Q statistic (significance level at $P=0.01$ ). The $I^{2}$ statistic was calculated to measure inconsistency across studies. The pooled effect size was estimated using either fixed-effects models or random-effects models in the presence of heterogeneity $\left(I^{2}>50 \%\right)$.

Subgroup analysis was performed by the method of psychological intervention (cognitive behavioral therapy [CBT] vs other psychological treatments), the use of systemic treatment (yes vs no), the severity of psoriasis before intervention (moderate-to-severe or PASI $>8$ vs mild or PASI $\leq 8$ ), and the format of therapy (in-person vs remote) to investigate the source of heterogeneities. Sensitivity analysis was conducted by estimating the pooled mean difference after deleting one study at a time. Publication bias was assessed using a funnel plot. Review Manager 5.3 (Copenhagen: The Nordic Cochrane Center, The Cochrane Collaboration) was used for meta-analysis. The significance level was 0.05 for all statistical tests.

\section{Results \\ Study selection}

A total of 4,156 articles were identified in our screening. Among these, 924 duplicate articles were excluded, and 3,118 citations were excluded after initial screening because they 
were not RCTs or the subjects and interventions were not related to our topic. Of the full-text articles, 114 were retained for further screening. Of these, 106 were excluded for various reasons (Figure 1). Eight RCTs with a total of 765 study participants were included in the final meta-analysis. ${ }^{19-23,25-27}$

\section{Characteristics of the included studies}

The characteristics of the included studies, involving 765 participants and published before January 2018, are summarized in Table 1. One study was conducted in USA, five in Europe, and two in Asia. The methods of intervention varied across the studies. Five studies were based on CBT, and the other three studies were based on other psychological therapies. The sample size of the intervention groups ranged from 20 to 86 (380 individuals in total), and control group size ranged from 20 to 83 (385 in total). The average age of the participants ranged from 37.3 to 56.7 years. The duration of the studies ranged from 6 weeks to 6 months. The intervention was conducted either individually or by group and was delivered either face-to-face or through the telephone or Internet. Five studies used PASI as the primary outcome, one used SAPASI, and two used both PASI and SAPASI. All studies reported changes in scores of clinical scales before and after the intervention.

\section{Main analysis}

Owing to the between-study heterogeneity $\left(I^{2}=79 \%\right)$, the random-effects model was used. As shown in Figure 2, the pooled mean difference of PASI reduction was $-1.36(95 \%$ CI: -2.52 to $-0.19 ; P=0.02)$, and the pooled mean difference of SAPASI reduction was 0.16 (95\% CI: -0.54 to 0.86 ; $P=0.64)$.

\section{Subgroup analysis}

Three factors were identified as significant confounders for the efficacy. As shown in Figure 3, the pooled estimate for the

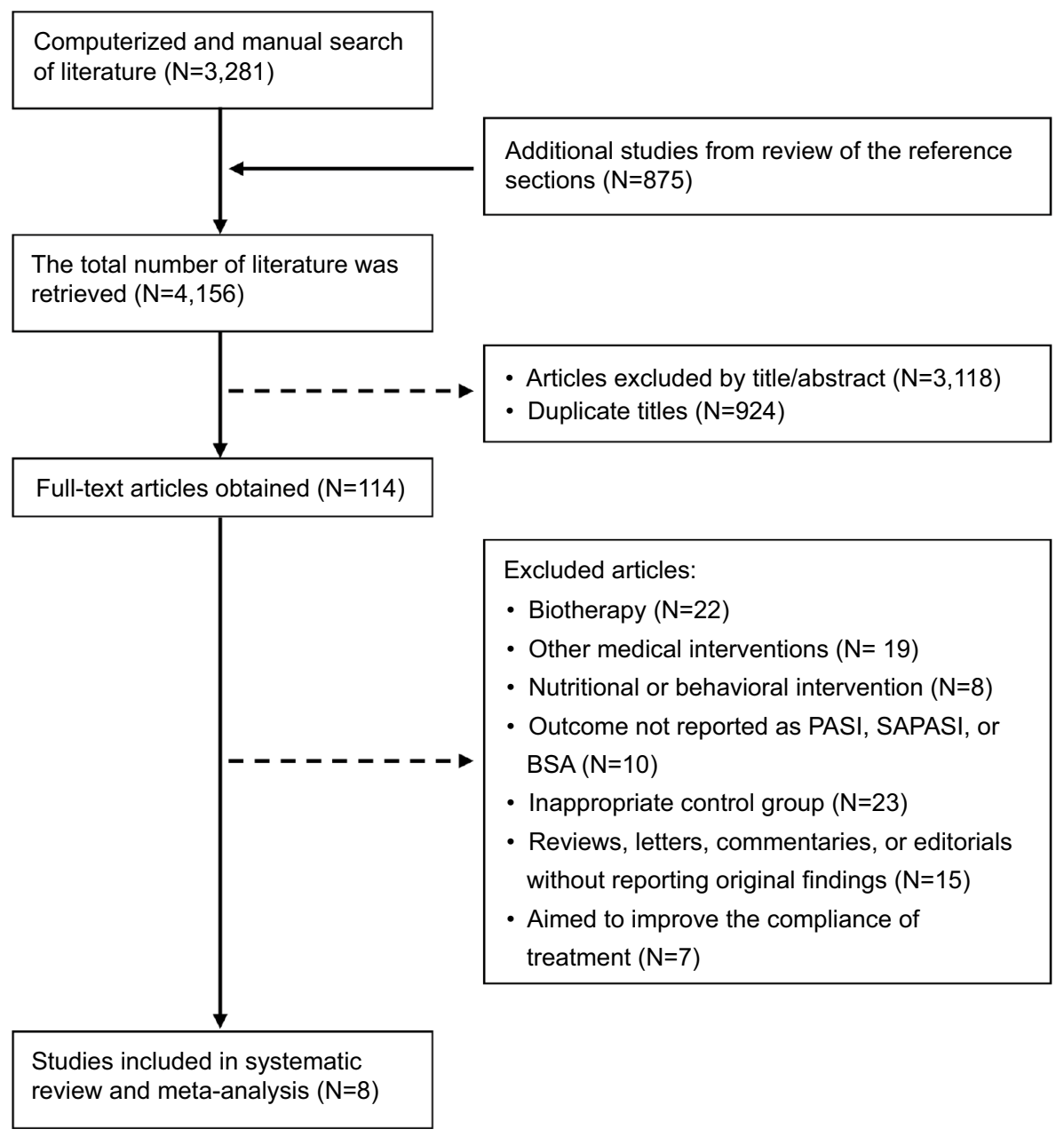

Figure I Selection process for study inclusion in the systematic review and meta-analysis.

Abbreviations: BSA, body surface area; PASI, Psoriasis Area and Severity Index; SAPASI, Self-administered Psoriasis Area and Severity Index. 
Table I Characteristics of included studies

\begin{tabular}{|c|c|c|c|c|c|c|c|c|}
\hline \multirow[t]{2}{*}{ Study } & \multirow{2}{*}{$\begin{array}{l}\text { Intervention } \\
\text { (duration) }\end{array}$} & \multirow{2}{*}{$\begin{array}{l}\text { Other treatments } \\
\text { during the intervention }\end{array}$} & \multirow[t]{2}{*}{ Outcomes } & \multicolumn{2}{|c|}{ Mean age (years) } & \multicolumn{2}{|c|}{ Baseline PASI/SAPASI } & \multirow[t]{2}{*}{ Jadad } \\
\hline & & & & Intervention & Control & Intervention & Control & \\
\hline $\begin{array}{l}\text { Zachariae et al } \\
(1996)^{19}\end{array}$ & $\begin{array}{l}\text { Individual CBT } \\
\text { (12 weeks) }\end{array}$ & No medication & PASI & $38.7 \pm 9.9$ & $39.5 \pm 11.1$ & $7.4 \pm 1.6$ & $8.1 \pm 2.7$ & 3 \\
\hline $\begin{array}{l}\text { Fortune et al } \\
(2002)^{20}\end{array}$ & $\begin{array}{l}\text { Group CBT } \\
\text { (6 weeks) }\end{array}$ & $\begin{array}{l}\text { Topical (coal tar, } \\
\text { calcipotriol, and } \\
\text { corticosteroids) and/ } \\
\text { or systemic (acitretin, } \\
\text { methotrexate, and } \\
\text { cyclosporine) }\end{array}$ & PASI & $42.7 \pm I I .6$ & $43.1 \pm 12.0$ & $10.5 \pm 2.7$ & $9.2 \pm 3.2$ & 2 \\
\hline $\begin{array}{l}\text { Vedhara et al } \\
(2007)^{21}\end{array}$ & $\begin{array}{l}\text { Telephone- } \\
\text { based emotional } \\
\text { disclosure } \\
(12 \text { weeks })\end{array}$ & $\begin{array}{l}\text { Topical (hydrocortisone), } \\
\text { systemic (methotrexate), } \\
\text { and/or Vitamin D } \\
\text { supplement }\end{array}$ & PASI & $48.0 \pm 15.0$ & $50.0 \pm 12.0$ & $7.0 \pm 3.8$ & $7.1 \pm 4.3$ & 2 \\
\hline $\begin{array}{l}\text { Bundy et al } \\
(20 \mid 3)^{22}\end{array}$ & $\begin{array}{l}\text { Web-based CBT } \\
\text { (6 weeks) }\end{array}$ & $\begin{array}{l}\text { I3\% no treatment; } 58 \% \\
\text { topical only; and } 29 \% \\
\text { topical and systemic }\end{array}$ & SAPASI & $45.8 \pm 12.6$ & $44.3 \pm 12.8$ & $8.2 \pm 6.8$ & $8.8 \pm 6.3$ & 3 \\
\hline $\begin{array}{l}\text { Larsen et al } \\
(20 \mid 4)^{23}\end{array}$ & $\begin{array}{l}\text { Telephone-based } \\
\text { motivational } \\
\text { interviewing } \\
(3 \text { months }) \\
\end{array}$ & $\begin{array}{l}\text { Topical, UV radiation, } \\
\text { exercise, stress } \\
\text { management, etc (details } \\
\text { not available) }\end{array}$ & $\begin{array}{l}\text { PASI and } \\
\text { SAPASI }\end{array}$ & $46.2 \pm 12.7$ & $46.5 \pm 13.0$ & $7.8 \pm 4.8$ & $8.4 \pm 4.0$ & 3 \\
\hline $\begin{array}{l}\text { Piaserico et al } \\
(2016)^{25}\end{array}$ & $\begin{array}{l}\text { CBT and } \\
\text { biofeedback } \\
\text { (8 weeks) }\end{array}$ & $\begin{array}{l}\text { Narrow-band UVB } \\
\text { phototherapy }\end{array}$ & PASI & $46.4 \pm 16.8$ & $56.7 \pm 22.0$ & $9.0 \pm 3.2$ & $9.1 \pm 3.7$ & 3 \\
\hline $\begin{array}{l}\text { van Beugen } \\
\text { et al }(20 \mid 6)^{27}\end{array}$ & $\begin{array}{l}\text { Internet-based } \\
\text { CBT (6 months) }\end{array}$ & $\begin{array}{l}\text { Systemic (including } \\
\text { etanercept) }\end{array}$ & $\begin{array}{l}\text { PASI and } \\
\text { SAPASI }\end{array}$ & $52.7 \pm I I .3$ & $53.5 \pm 13.8$ & $6.0 \pm 5.6$ & $4.2 \pm 2.9$ & 3 \\
\hline $\begin{array}{l}\text { Singh et al } \\
(2017)^{26}\end{array}$ & $\begin{array}{l}\text { Group } \\
\text { multiprofessional } \\
\text { education } \\
\text { (6 months) }\end{array}$ & $\begin{array}{l}\text { Topical (coal tar, } \\
\text { calcipotriol, and } \\
\text { clobetasol), and/or } \\
\text { systemic (methotrexate, } \\
\text { acitretin, and cyclosporine) }\end{array}$ & PASI & $37.3 \pm I 4.8$ & $39.6 \pm 14.4$ & $9.6 \pm 5.5$ & $8.9 \pm 7.9$ & 2 \\
\hline
\end{tabular}

Abbreviations: CBT, cognitive behavioral therapy; PASI, Psoriasis Area and Severity Index; SAPASI, Self-administered Psoriasis Area and Severity Index.

A



B

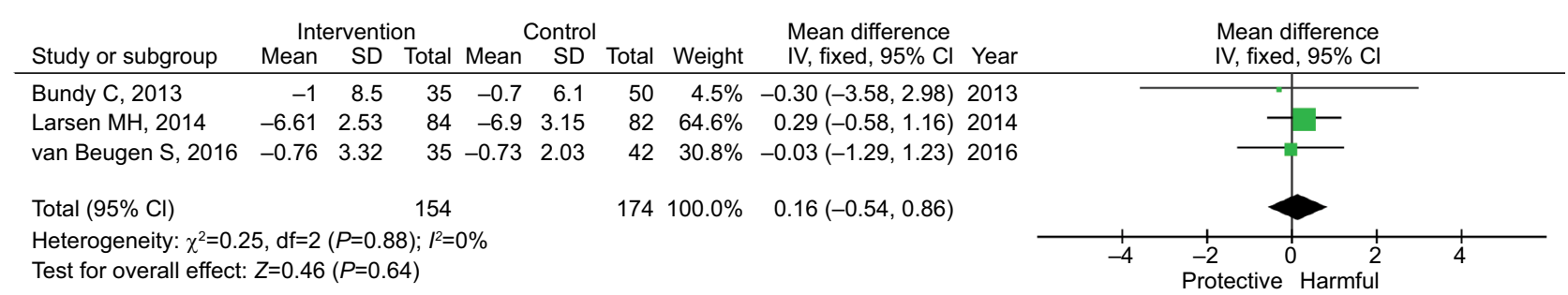

Figure 2 Pooled estimates of the efficacy of the psychological intervention by outcome measures.

Note: (A) PASI and (B) SAPASI.

Abbreviations: PASI, Psoriasis Area and Severity Index; SAPASI, Self-administered Psoriasis Area and Severity Index. 
A

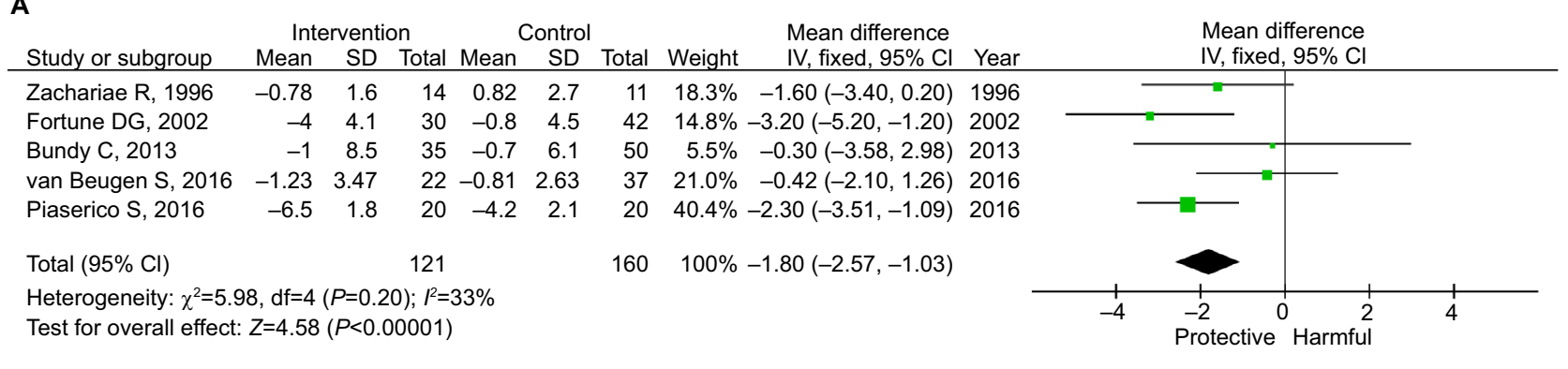

B

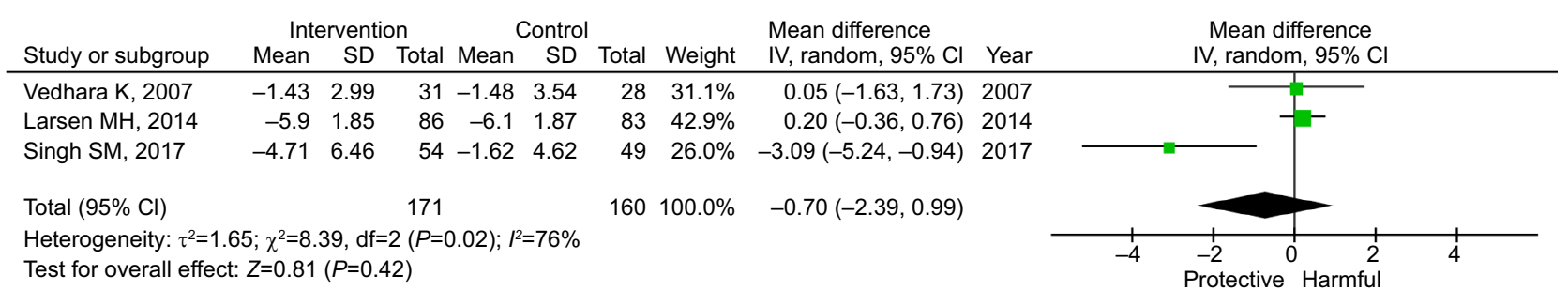

Figure 3 Subgroup analysis by the method of intervention. Notes: (A) CBT. (B) Non-CBT psychological intervention. Abbreviation: $\mathrm{CBT}$, cognitive behavioral therapy.

five studies using CBT was -1.80 (95\% CI: -2.57 to -1.03 ; $P<0.001)$, whereas the pooled estimate for the three studies using other psychological interventions was -0.70 (95\% CI: -2.39 to $0.99 ; P=0.42$ ). CBT is further grouped by the use of systemic treatment. As shown in Figure 4, systemic treatment did not synergistically enhance the efficacy of CBT. The effect size of CBT was similar in those with and without systemic medication, although one of the pooled estimates was not statistically significant.

As shown in Figure 5, the pooled estimates for mild and moderate-to-severe psoriasis were -1.95 (95\% CI: -3.91 to $0.00 ; P=0.05)$ and -0.61 (95\% CI: -1.61 to $0.38 ; P=0.23)$, respectively. As shown in Figure 6, the pooled estimates for in-person and remote intervention were -2.03 (95\% CI: -2.77 to $-1.29 ; P<0.001)$ and $0.17(95 \% \mathrm{CI}:-0.35$ to 0.70 ; $P=0.52$ ), respectively.

\section{Sensitivity analysis}

Sensitivity analysis showed a pooled mean difference ranging from -1.08 to -1.70 (Figure $\mathrm{S} 1$ ). When deleting the study by Fortune et al, ${ }^{20}$ Piaserico et al, ${ }^{25}$ or Singh et al, ${ }^{26}$ the pooled estimate became marginally significant $(P=0.06-0.07)$. When deleting other studies, the pooled estimate remained significant $(P<0.05)$.

\section{Quality and bias assessment}

The Jadad score ranged from 2 to 3 for included studies (Table 1). Owing to the nature of the psychological intervention, blinding to patients or investigators was not applicable. Four studies explicitly claimed that the severity of psoriasis was assessed by blinded physicians (Table 2). Four studies claimed the use of a random number table or computer-generated random number. Publication bias was not supported by the funnel plot (Figure S2).

\section{Discussion}

In this systematic review and meta-analysis examining the efficacy of psychological interventions to relieve psoriasis, the results support the efficacy in general. Notably, findings show that CBT-based intervention is effective; in contrast, non-CBT-based interventions are not found to be effective. Systemic treatment does not further enhance the efficacy of CBT. Similarly, in-person interventions are effective in comparison to remote interventions. More importantly, the effect size among patients with moderate-to-severe psoriasis (or baseline PASI >8) is larger than the effect among those with mild psoriasis (or baseline PASI $\leq 8$ ). Overall, this is the first analysis that examine the efficacy of psychological interventions for psoriasis patients. The supportive results add to the strong imperative to promote psychological care among patients with psoriasis.

Among these factors, we identified three significant confounders for efficacy: the method of intervention (CBT vs non-CBT-based intervention), the location of the intervention (in-person vs remote intervention), and baseline psoriasis severity (mild vs moderate-to-severe). The subgroup analysis 
A

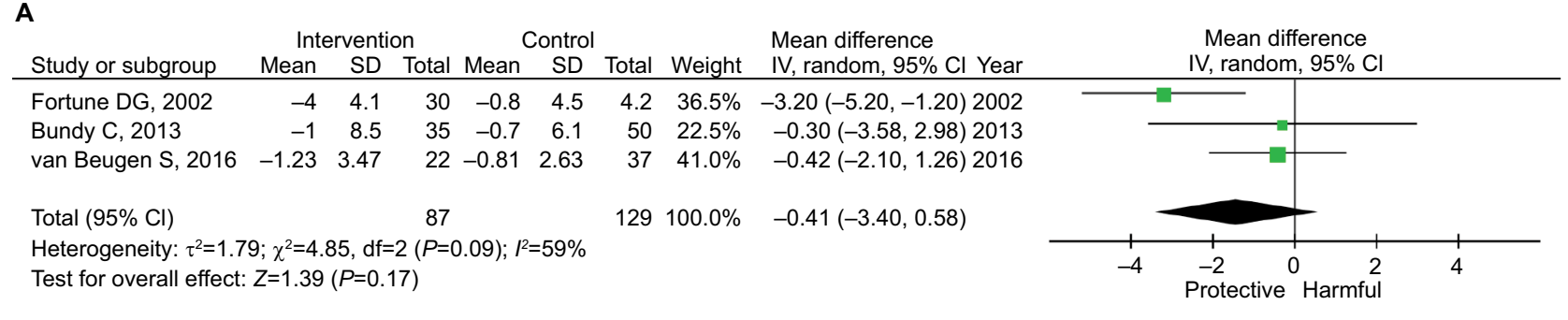

B

\begin{tabular}{|c|c|c|c|c|c|c|c|c|c|c|c|c|c|}
\hline \multirow{2}{*}{ Study or subgroup } & \multicolumn{3}{|c|}{ Intervention } & \multicolumn{3}{|c|}{ Control } & \multicolumn{2}{|r|}{ Mean difference } & & \multirow{2}{*}{\multicolumn{3}{|c|}{$\begin{array}{l}\text { Mean difference } \\
\text { IV, fixed, } 95 \% \mathrm{Cl}\end{array}$}} & \\
\hline & Mean & SD & & Mean & & Iotal & Vvelght & IV, fixed, 95\% Cl Year & & & & & \\
\hline Zachariae R, 1996 & -0.78 & 1.6 & 14 & 0.82 & 2.7 & 11 & $31.1 \%$ & $-1.60(-3.40,0.20) 1996$ & & & & & \\
\hline Piaserico S, 2016 & -6.5 & 1.8 & 20 & -4.2 & 2.1 & 20 & $68.9 \%$ & $-2.30(-3.15,-1.09) 2016$ & & & & & \\
\hline Total $(95 \% \mathrm{Cl})$ & & & 34 & & & 31 & $100.0 \%$ & $-2.08(-3.09,-1.08)$ & & & & & \\
\hline \multicolumn{9}{|c|}{$\begin{array}{l}\text { Heterogeneity: } \chi^{2}=0.40, \mathrm{df}=1(P=053) ; l^{2}=0 \% \\
\text { Test for overall effect: } Z=4.06(P<0.0001)\end{array}$} & -4 & -2 & 0 & 2 & 4 \\
\hline & & & & & & & & & & tect & & arm & \\
\hline
\end{tabular}

Figure 4 Subgroup analysis by the use of systemic treatment among those receiving CBT.

Notes: (A) Some received systemic treatment. (B) No systemic treatment.

Abbreviation: $\mathrm{CBT}$, cognitive behavioral therapy.

A

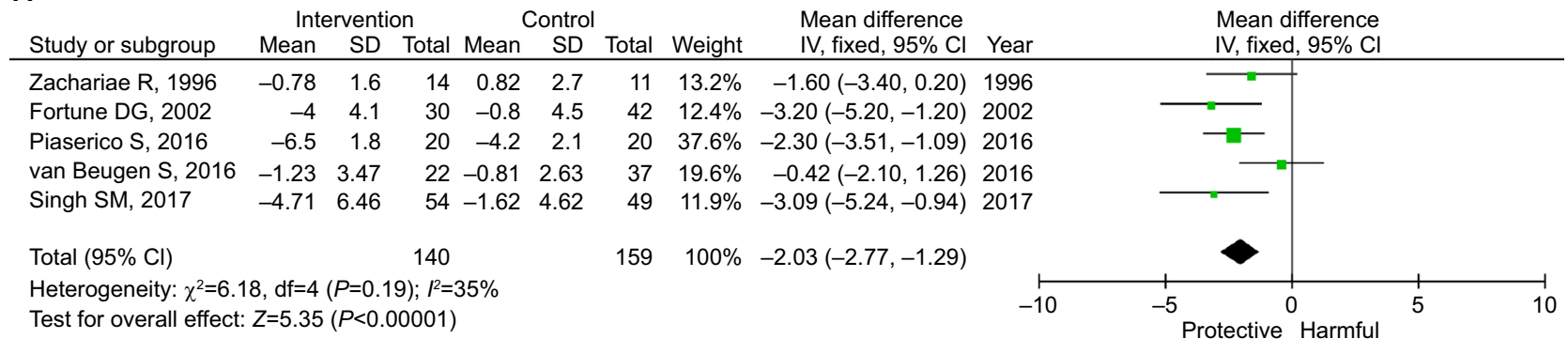

B

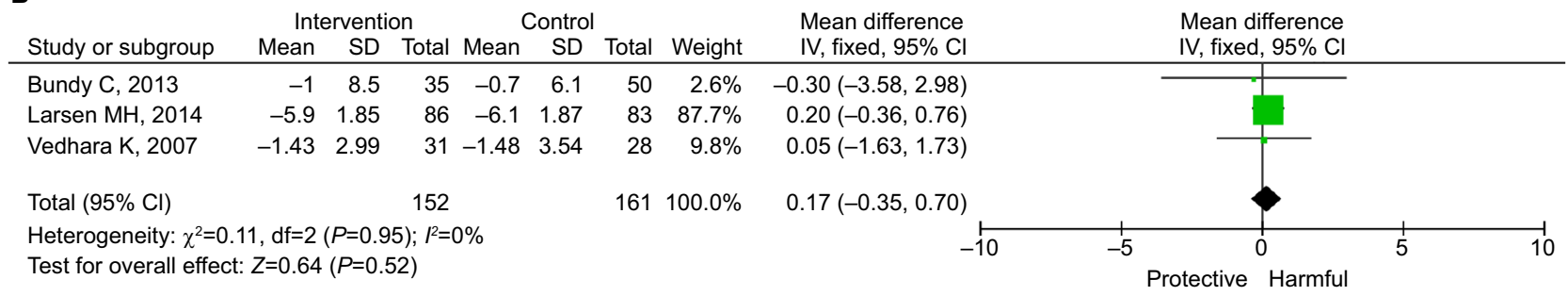

Figure 5 Subgroup analysis by the severity of psoriasis before intervention.

Notes: (A) Moderate-to-severe or baseline mean PASI $>8$. (B) Mild or baseline mean PASI $\leq 8$.

Abbreviation: PASI, Psoriasis Area and Severity Index.

shows that CBT, rather than other specific psychological interventions, is effective in PASI reduction with a moderate effect size. There are a variety of psychological intervention methods that were widely applied nowadays, among which $\mathrm{CBT}$ is more widely recognized in the field. CBT can reduce the stigma and confusion surrounding affective and anxiety responses to the disease, ${ }^{28,29}$ and it may improve psoriasis severity by inhibiting the inflammation associated with depression and anxiety. In addition, CBT provides a tailored approach to correct misconceptions and expand knowledge about the nature of psoriasis; $;^{30,31}$ for example, believing it to be contagious. Moreover, CBT may be helpful in tackling feelings of despondency and hopelessness in patients, making them more participative in their treatments. In contrast, other methods of psychological intervention, which mainly focus on one single perspective of intervention, such as treatment compliance, health education, or psychological care for the comfort of the patient, do not have proven efficacy. This 
A

\begin{tabular}{|c|c|c|c|c|c|c|c|c|c|c|c|c|}
\hline \multirow{3}{*}{$\begin{array}{l}\text { Study or subgroup } \\
\text { Fortune DG, } 2002\end{array}$} & \multicolumn{3}{|c|}{ Intervention } & \multicolumn{3}{|c|}{ Control } & \multirow{2}{*}{ Weight } & \multicolumn{2}{|l|}{ Mean difference } & \multirow{2}{*}{\multicolumn{2}{|c|}{$\begin{array}{c}\text { Mean difference } \\
\text { IV, random, } 95 \% \mathrm{Cl}\end{array}$}} & \\
\hline & Mean & SD & Total & Mean & & Total & & IV, random, 95\% Cl & Year & & & \\
\hline & -4 & 4.1 & 30 & -0.8 & 4.5 & 42 & $22.6 \%$ & $-3.20(-5.20,-1.20)$ & 2002 & -7 & & \\
\hline Larsen MH, 2014 & -5.9 & 1.85 & 86 & -6.1 & 1.87 & 83 & $28.9 \%$ & $0.20(-0.36,0.76)$ & 2014 & & - & \\
\hline Singh SM, 2017 & -4.71 & 6.46 & 54 & -1.62 & 4.62 & 49 & $21.8 \%$ & $-3.09(-5.24,-0.94)$ & 2017 & & & \\
\hline Total $(95 \% \mathrm{Cl})$ & & & 190 & & & 194 & $100 \%$ & $-1.95(-3.91,0.00)$ & & & & \\
\hline $\begin{array}{l}\text { Heterogeneity: } \tau^{2}=3 \\
\text { Test for overall effec }\end{array}$ & $\begin{array}{l}z \chi^{2}=26 \\
Z=1.96\end{array}$ & $\begin{array}{l}.95, \mathrm{df} \\
(P=0.0\end{array}$ & $\begin{array}{l}\mathrm{f}=3(P< \\
05)\end{array}$ & .000 & $; l^{2}$ & & & & -10 & -5 Prote & $e^{0}$ Harmful & 5 \\
\hline
\end{tabular}

B

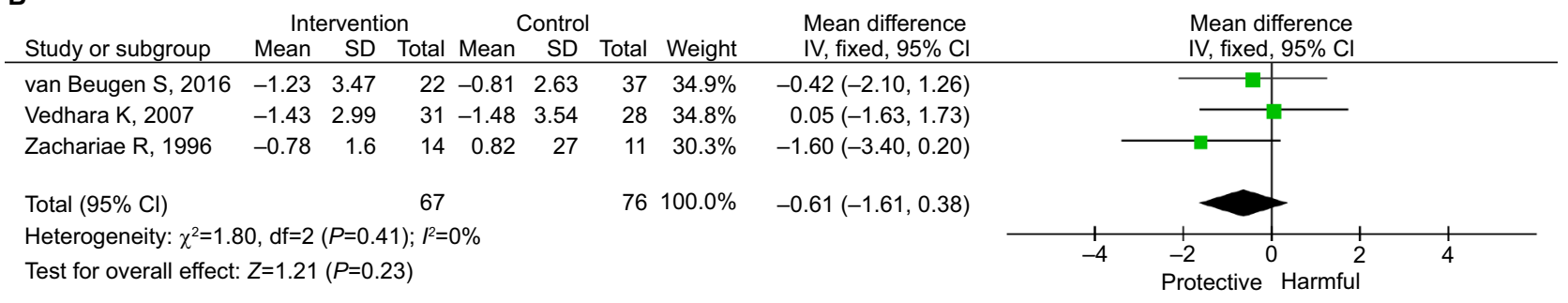

Figure 6 Subgroup analysis by the location of intervention.

Notes: (A) In-person intervention. (B) Remote intervention.

Table 2 Methodological quality of included studies

\begin{tabular}{|c|c|c|c|c|c|c|c|c|}
\hline \multirow[b]{2}{*}{ Included studies } & \multicolumn{3}{|l|}{ Blinding } & \multicolumn{5}{|l|}{ Risk of bias } \\
\hline & Participants & Investigators & $\begin{array}{l}\text { Outcome } \\
\text { assessors }\end{array}$ & $\begin{array}{l}\text { Random } \\
\text { sequence } \\
\text { generation }\end{array}$ & $\begin{array}{l}\text { Allocation } \\
\text { concealment }\end{array}$ & $\begin{array}{l}\text { Incomplete } \\
\text { outcome data }\end{array}$ & $\begin{array}{l}\text { Selecting } \\
\text { reporting }\end{array}$ & $\begin{array}{l}\text { Other } \\
\text { biases }\end{array}$ \\
\hline Zachariae et al $(1996)^{19}$ & No & No & Yes & Unclear & High & Low & Low & Unclear \\
\hline Fortune et al $(2002)^{20}$ & No & No & No & High & High & Low & Low & Unclear \\
\hline Vedhara et al $(2007)^{2 !}$ & No & No & Yes & Unclear & High & Low & High & Unclear \\
\hline Bundy et al $(2013)^{22}$ & No & No & No & Low & High & Low & Low & Unclear \\
\hline Larsen et al $(2014)^{23}$ & No & No & Yes & Unclear & High & Low & Low & Unclear \\
\hline Piaserico et al $(2016)^{25}$ & No & No & Yes & Low & High & Low & High & Unclear \\
\hline van Beugen et al $(2016)^{27}$ & No & No & No & Low & High & Low & Low & Unclear \\
\hline Singh et al $(20 \mid 7)^{26}$ & No & No & No & Low & High & Low & High & Unclear \\
\hline
\end{tabular}

may be due to a lot of reasons, such as lack of theory-based formation or shooting the wrong target.

Although the results show that CBT is effective, we cannot draw the simplistic conclusion that $\mathrm{CBT}$ is a universal effective therapy to all psoriasis patients because CBT is tailored for individual patients and there is heterogeneity in the delivery of this method. Since the mechanism of the interaction between psoriasis and mental disorders is quite diverse individually, we cannot view and treat their interaction simplistically. Specific interventions should be tailored according to the specific causes of mental consequences for particular psoriasis patients. For instance, some of the patients are haunted by particular symptoms contributing to mental illness, such as pain and itch, and so clinicians should emphasize more about targeting the alleviation of annoying symptoms. ${ }^{32}$ Some patients have impaired social and sexual activities owing to the appearance of psoriasis (the scaly rash and erythema $)^{16}$ and some are ashamed of the disease because of misunderstanding, stigmatization, and social discrimination..$^{33}$ In these situations, psychological intervention, especially CBT, may effectively improve psoriasis through the mediating effects of the psychological function. For psoriasis patients with many comorbidities and high systemic inflammatory status, an early start with biologics such as TNF- $\alpha$ could be a comprehensive way to manage the "syndemics" of psoriasis and mental disorders. ${ }^{34,35}$ However, more evidence is needed in the future.

The result that in-person psychological treatments are more effective compared with tele-based intervention can be easily understood since in-person conversation and therapy 
are better in guiding patients to talk about the trouble, to accept the illness, and to receive treatment.

Interestingly, we found that psychological intervention is more effective among patients with moderate-to-severe psoriasis (effect size: $-1.95, P=0.05$ ) rather than those with mild psoriasis (effect size: $-0.61 ; P=0.23$ ), which had not been reported previously. Previous studies reported debated evidence on the association of severity of psoriasis with psychosocial status. Some studies showed that illness of psoriasis is not always proportional to the severity of psoriasis. ${ }^{36}$ However, we cannot add evidence on this association because there is only one enrolled study that strictly evaluated the psychological status of possible subjects and enrolled them as a prerequisite at baseline of the trail. ${ }^{21}$ Alternatively, we can view our result in a relatively independent way. There is one mechanism among all the possible explanations that is more prominent in severe psoriasis, which is the higher active "syndemics" between psoriasis, mental illness, and other related comorbidities. Compared to mild psoriasis, severe psoriasis tended to have more systemic inflammatory involvement ${ }^{37-39}$ and more inflammatory cytokine activation, which can mutually influence both psoriasis and mental disorders, such as levels of $\gamma$-interferon, ${ }^{40,41}$ IL-17, ${ }^{42,43}$ and neuron growth factor. ${ }^{44}$ For severe patients who may have more comorbidities and higher systemic inflammatory status, psychological treatment may help to ease the underlying comechanism and to alleviate psoriasis symptoms.

The primary limitation of the meta-analysis is that there are strong research heterogeneities across the included studies with respect to the basic treatment and the method, delivery, duration, and format of the psychological interventions. Even for CBT studies, the interventions were designed and implemented with great variation. At the study level, an open-label design was used for the included studies, although some mentioned that the outcome assessors were blinded.

\section{Conclusion}

CBT is effective in the treatment of psoriasis in terms of area and severity reduction, whereas non-CBT psychological interventions are not effective. The efficacy of CBT is not further enhanced by systemic treatment. The effect size of the psychological intervention is stronger in patients with moderateto-severe psoriasis in comparison to those with mild psoriasis.

\section{Ethical statement}

This is a systematic review and meta-analysis of published paper, and the ethical approval is not applicable. Informed consent is not applicable because this is a review paper.

\section{Acknowledgments}

This work was supported by the Ministry of Science and Technology of the People's Republic of China (2015FY111100 and 2016YFC0900802) and the Department of Science and Technology of Hunan Province (2018SK2086).

\section{Disclosure}

The authors report no conflicts of interest in this work.

\section{References}

1. Williams HC. Evidence-Based Dermatology. 3rd edn. Oxford: John Wiley \& Sons, Ltd; 2014.

2. Nijsten T, Feldman S, Stern R. Members of the National psoriasis Foundation: more extensive disease and better informed about treatment options. J Invest Dermatol. 2007;127(7):1809-1809.

3. Yosipovitch G, Goon A, Wee J, Chan YH, Goh CL. The prevalence and clinical characteristics of pruritus among patients with extensive psoriasis. Br J Dermatol. 2000;143(5):969-973.

4. Zeng J, Luo S, Huang Y, Lu Q. Critical role of environmental factors in the pathogenesis of psoriasis. J Dermatol. 2017;44(8):863-872.

5. Pfohler C, Muller CS, Vogt T. Psoriasis vulgaris and psoriasis pustulosa - epidemiology, quality of life, comorbidities and treatment. Curr Rheumatol Rev. 2013;9(1):2-7.

6. Sampogna F, Tabolli S, Mastroeni S, et al. Quality of life impairment and psychological distress in elderly patients with psoriasis. Dermatology. 2007;215(4):341-347.

7. Lee MS, Lin RY. The risk of incident depression and anxiety in patients with psoriasis: a population-based cohort study. J Am Acad Dermatol. 2012;66(4):Ab205-Ab205.

8. Johnsson H, McInnes IB, Sattar N. Cardiovascular and metabolic risks in psoriasis and psoriatic arthritis: pragmatic clinical management based on available evidence. Ann Rheum Dis. 2012;71(4):480-483.

9. Snast I, Reiter O, Atzmony L, et al. Psychological stress and psoriasis: a systematic review and meta-analysis. Br J Dermatol. 2018;178(5):1044-1055.

10. Romeo U, Richetta A, Rocchetti F, et al. Oral features in patients with psoriasis: an observational study. Minerva Stomatol. 2018;67(1):12-19.

11. Zeng C, Wen B, Hou G, et al. Lipidomics profiling reveals the role of glycerophospholipid metabolism in psoriasis. GigaScience. 2017;6(10):1-11.

12. Wan MT, Shin DB, Hubbard RA, Noe MH, Mehta NN, Gelfand JM. Psoriasis and the risk of diabetes: a prospective population-based cohort study. J Am Acad Dermatol. 2018;78(2):e311:315-322.

13. Humphreys F, Humphreys MS. Psychiatric morbidity and skin disease: what dermatologists think they see. Br J Dermatol. 1998;139(4): 679-681.

14. Yang YW, Keller JJ, Lin HC. Medical comorbidity associated with psoriasis in adults: a population-based study. $\mathrm{Br} J$ Dermatol. 2011;165(5):1037-1043.

15. Dominguez PL, Han J, Li T, Ascherio A, Qureshi AA. Depression and the risk of psoriasis in US women. $J$ Eur Acad Dermatol Venereol. 2013;27(9):1163-1167.

16. Devrimci-Ozguven H, Kundakci N, Kumbasar H, Boyvat A. The depression, anxiety, life satisfaction and affective expression levels in psoriasis patients. J Eur Acad Dermatol Venerol. 2000;14(4):267-271.

17. Kurd SK, Troxel AB, Crits-Christoph P, Gelfand JM. The risk of depression, anxiety, and suicidality in patients with psoriasis: a populationbased cohort study. Arch Dermatol. 2010;146(8):891-895.

18. Singer M, Bulled N, Ostrach B, Mendenhall E. Syndemics and the biosocial conception of health. Lancet. 2017;389(10072):941-950.

19. Zachariae R, Øster H, Bjerring P, Kragballe K. Effects of psychologic intervention on psoriasis: a preliminary report. $\mathrm{J} \mathrm{Am} \mathrm{Acad} \mathrm{Dermatol.}$ 1996;34(6):1008-1015. 
20. Fortune DG, Richards HL, Kirby B, Bowcock S, Main CJ, Griffiths CE. A cognitive-behavioural symptom management programme as an adjunct in psoriasis therapy. Br J Dermatol. 2002;146(3):458-465.

21. Vedhara K, Morris RM, Booth R, Horgan M, Lawrence M, Birchall $\mathrm{N}$. Changes in mood predict disease activity and quality of life in patients with psoriasis following emotional disclosure. J Psychosom Res. 2007;62(6):611-619.

22. Bundy C, Pinder B, Bucci S, Reeves D, Griffiths CE, Tarrier N. A novel, web-based, psychological intervention for people with psoriasis: the electronic targeted intervention for psoriasis (eTIPs) study. $\mathrm{Br} J$ Dermatol. 2013;169(2):329-336.

23. Larsen MH, Krogstad AL, Aas E, Moum T, Wahl AK. A telephonebased motivational interviewing intervention has positive effects on psoriasis severity and self-management: a randomized controlled trial Br J Dermatol. 2014;171(6):1458-1469.

24. Clark HD, Wells GA, Huët C, et al. Assessing the quality of randomized trials: reliability of the Jadad scale. Control Clin Trials. 1999;20(5):448-452.

25. Piaserico S, Marinello E, Dessi A, Linder MD, Coccarielli D, Peserico A. Efficacy of biofeedback and cognitive-behavioural therapy in psoriatic PatientsA single-blind, randomized and controlled study with added narrow-band ultraviolet B therapy. Acta Derm Venereol. 2016;96(217):91-95.

26. Singh SM, Narang T, Vinay K, et al. Clinic-based group multi-professional education causes significant decline in psoriasis severity: a randomized open label pilot study. Indian Dermatol Online J. 2017;8(6):454-459.

27. van Beugen S, Ferwerda M, Spillekom-van Koulil S, et al. Tailored Therapist-Guided Internet-based cognitive behavioral treatment for psoriasis: a randomized controlled trial. Psychother Psychosom. 2016;85(5):297-307.

28. Shimotsu S, Horikawa N, Emura R, et al. Effectiveness of group cognitive-behavioral therapy in reducing self-stigma in Japanese psychiatric patients. Asian J Psychiatr. 2014;10:39-44.

29. Staring AB, Ter Huurne MA, van der Gaag M. Cognitive behavioral therapy for negative symptoms (CBT-n) in psychotic disorders: a pilot study. J Behav Ther Exp Psychiatry. 2013;44(3):300-306.

30. Bevan A, Oldfield VB, Salkovskis PM. A qualitative study of the acceptability of an intensive format for the delivery of cognitivebehavioural therapy for obsessive-compulsive disorder. $\mathrm{Br} \mathrm{J} \mathrm{Clin}$ Psychol. 2010;49(2):173-191.

31. Hara KM, Westra HA, Aviram A, Button ML, Constantino MJ, Antony MM. Therapist awareness of client resistance in cognitivebehavioral therapy for generalized anxiety disorder. Cogn Behav Ther. 2015;44(2):162-174.
32. Henry AL, Kyle SD, Bhandari S, Chisholm A, Griffiths CE, Bundy C. Measurement, classification and evaluation of sleep disturbance in psoriasis: a systematic review. PLoS One. 2016;11(6):e0157843.

33. Böhm D, Stock Gissendanner S, Bangemann K, et al. Perceived relationships between severity of psoriasis symptoms, gender, stigmatization and quality of life. J Eur Acad Dermatol. 2013;27(2): $220-226$.

34. Abbott R, Whear R, Nikolaou V, et al. Tumour necrosis factor- $\alpha$ inhibitor therapy in chronic physical illness: a systematic review and meta-analysis of the effect on depression and anxiety. J Psychosom Res. 2015;79(3):175-184.

35. Kannan S, Heller MM, Lee ES, Koo JY. The role of tumor necrosis factor-alpha and other cytokines in depression: what dermatologists should know. J Dermatolog Treat. 2013;24(2):148-152.

36. Kimball AB, Jacobson C, Weiss S, Vreeland MG, Wu Y. The psychosocial burden of psoriasis. Am J Clin Dermatol. 2005;6(6): 383-392.

37. Wu R, Zeng J, Yuan J, et al. MicroRNA-210 overexpression promotes psoriasis-like inflammation by inducing Th1 and Th17 cell differentiation. J Clin Invest. 2018;128(6):2551-2568.

38. Peng C, Zhang S, Lei L, et al. Epidermal CD147 expression plays a key role in IL-22-induced psoriatic dermatitis. Sci Rep. 2017;7(1): 44172.

39. Liu P, He Y, Wang H, et al. The expression of mCTLA-4 in skin lesion inversely correlates with the severity of psoriasis. J Dermatol Sci. 2018;89(3):233-240.

40. Gunderson AJ, Mohammed J, Horvath FJ, Podolsky MA, Anderson CR, Glick AB. CD8(+) T cells mediate RAS-induced psoriasis-like skin inflammation through IFN- $\gamma$. J Invest Dermatol. 2013;133(4): 955-963.

41. Kryczek I, Bruce AT, Gudjonsson JE, et al. Induction of IL-17+ T cell trafficking and development by IFN-gamma: mechanism and pathological relevance in psoriasis. J Immunol. 2008;181(7):4733-4741.

42. Onderdijk AJ, Baerveldt EM, Kurek D, et al. IL-4 downregulates IL-1 $\beta$ and IL- 6 and induces GATA3 in psoriatic epidermal cells: route of action of a Th2 cytokine. J Immunol. 2015;195(4):1744-1752.

43. Deng Y, Chang C, Lu Q. The inflammatory response in psoriasis: a comprehensive review. Clin Rev Allergy Immunol. 2016;50(3): 377-389.

44. Raychaudhuri SP, Raychaudhuri SK. Role of NGF and neurogenic inflammation in the pathogenesis of psoriasis. Prog Brain Res. 2004; $146: 433-437$. 


\section{Supplementary materials}

Overall

Zachariae R, 1996

Fortune DG, 2002

Vedhara K, 2007

Larsen MH, 2014

van Beugen S, 2016

Piaserico S, 2016

Singh SM, 2017

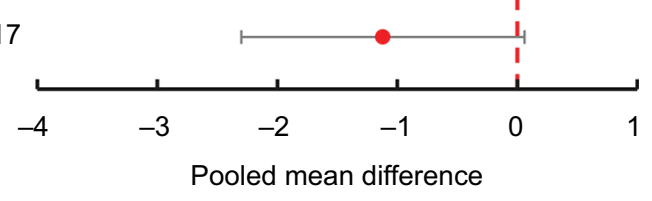

Figure SI Pooled estimates and $95 \% \mathrm{Cls}$ in sensitivity analysis.

Note: Each bar signifies the pooled estimate when deleting the corresponding study.

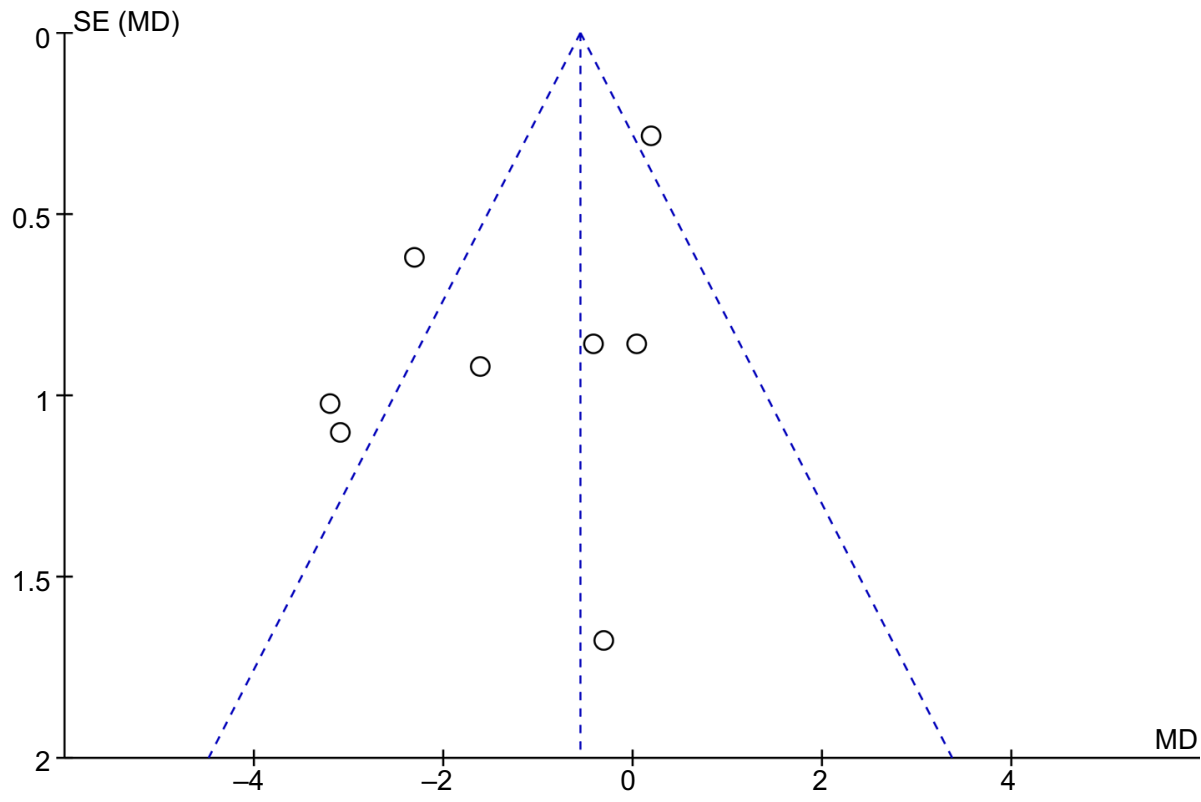

Figure S2 Funnel plot to assess the publication bias.

\section{Publish your work in this journal}

Psychology Research and Behavior Management is an international, peerreviewed, open access journal focusing on the science of psychology and its application in behavior management to develop improved outcomes in the clinical, educational, sports and business arenas. Specific topics covered in the journal include: Neuroscience, memory and decision making; Behavior modification and management; Clinical applications; Business and sports performance management; Social and developmental studies; Animal studies. The manuscript management system is completely online and includes a very quick and fair peer-review system, which is all easy to use. Visit http://www. dovepress.com/testimonials.php to read real quotes from published authors.

Submit your manuscript here: https://www.dovepress.com/psychology-research-and-behavior-management-journal 